\title{
LEGISLAÇÃO PENAL DE EMERGÊNCIA: CRISE DE INTERVENÇÃO MÍNIMA DO DIREITO PENAL
}

\author{
EMERGENCY CRIMINAL LEGISLATION: CRISIS OF MINIMAL INTERVENTION OF \\ CRIMINAL LAW.
}

\author{
Eloisa Morgana dos Santos Mendes ${ }^{1}$ \\ Raíssa Braga Campelo²
}

\begin{abstract}
RESUMO
O presente trabalho visa analisar como a característica da emergência no tocante a elaboração de leis influencia a crise de intervenção mínima, a qual o direito penal brasileiro se encontra. Para isso, será abordada a emergência em sua origem e fundamentação, em sequência será explicado como a mídia manipula o telespectador e contribui para a construção de uma população amedrontada, denominada de "Sociedade do Risco", e na materialização do criminoso como "inimigo social", e como isso colabora para uma política voltada para o clamor social e para leis emergenciais. Por fim o texto estabelece a relação entre a emergência e a crise de intervenção mínima, elencando as consequências de uma política emergencial que origina uma máxima intervenção penal, fundamentada pelo expansionismo, simbolismo e hiperinflação legislativa penal, apontando alguns exemplos concretos de leis de cunho emergenciais, para ao final verificar como todas essas características da emergência tornam o direito penal rígido e violador, voltado ao punitivismo e deixando à margem os princípios fundamentais e garantivistas.
\end{abstract}

Palavras-chave: Emergência. Intervenção Mínima. Direito Penal. Risco. Criminalidade. Simbolismo penal.

\section{ABSTRACT}

\footnotetext{
${ }^{1}$ Graduada em Direito pelo Centro Universitário do Vale do Ipojuca- UNIFAVIP WYDEN. E-mail: eloisamorgana3@gmail.com

${ }^{2}$ Mestre em Gestão Empresarial pela Faculdade de Boa Viagem - FBV DeVry. Especialista em Ciências Criminais pelo Complexo Jurídico Damásio de Jesus. Professora Universitária no Curso de Bacharelado em Direito do Centro Universitário do Vale do Ipojuca - DeVry | UNIFAVIP. Professora Universitária do Curso de Bacharelado em Direito na Faculdade de Direito de Garanhuns - AESGA. Professora Universitária na UPE Garanhuns - Campus Arcoverde.
} 
This text aims at analyzing how the emergency characteristic in relation to the elaboration of laws influences the crisis of minimum intervention, in which Brazilian criminal law is. In order to do so, the emergence of its source and its rationale will be explored, in sequence it will be explained how the media manipulates the viewer and contributes to the construction of a frightened population, known as the "Risk Society", and in the materialization of the criminal as "social enemy", and how this contributes to a policy focused on social outcry and emergency laws. Finally, the text establishes the relationship between the emergency and the crisis of minimal intervention, highlighting the consequences of an emergency policy that leads to maximum criminal intervention, based on expansionism, symbolism and criminal legislative hyperinflation, pointing to some concrete examples of emergency laws, in order to verify how all these characteristics of the emergency make criminal law rigid and violating, aimed at punitivism and leaving aside the fundamental and guaranteeing principles.

Keywords: Emergency. Minimum Intervention. Criminal Law. Risk. Criminality. Criminal Symbolism.

\section{INTRODUÇÃO}

Um dos maiores problemas enfrentados pelo direito Penal consiste na necessidade de regulamentar as relações entre indivíduos que convivem em meio social. Diante disso, recai sobre o Estado o jus puniendi, que é o poder-dever de punir aqueles que violem a ordem social.

Para a efetivação do jus puniendi, o Estado utiliza-se do direito penal, por ser o ramo do direito que possui característica de sancionador, contudo em decorrência das modificações e do desenvolvimento da sociedade atual, o que se observa é um aumento da criminalidade, essa que passa a ser transmitida pela mídia de forma infundada e constante, deixando seus telespectadores com medo a ponto de pressionar o Estado a buscar meios de controle da violência.

Dessa característica de risco constante, oriunda do medo, surge a urgência de inibir a criminalidade e deixar a sociedade, mesmo que de forma momentânea, tranquila, para isso o Estado utiliza a emergência legislativa, que nada mais é do que a elaboração de leis rápidas motivadas por casos que chocam profundamente a população, e que objetivam transmitir uma sensação de segurança e de um Estado "atuante". A emergência viola princípios constitucionais, que limitam a atuação do 
Estado na vida dos indivíduos e origina a crise de intervenção mínima do direito penal brasileiro.

Tendo por base tal entendimento, busca-se responder a seguinte problemática de pesquisa: Como a legislação de emergência influencia o surgimento da crise de intervenção mínima do direito penal? Para isso, será utilizado uma análise da sociedade atual e como é utilizado o direito penal no ordenamento jurídico contemporâneo.

O presente artigo, objetiva verificar como a legislação de emergência influencia o surgimento da crise de intervenção mínima do direito penal, mediante os seguintes objetivos específicos: a) Discorrer acerca do direito penal de emergência; b)Discutir sobre o princípio da intervenção mínima e c) Apontar como a utilização da emergência intensifica a crise de intervenção mínima do direito penal.

Esta pesquisa se justifica pelo fato de proporcionar uma análise ao processo de utilização da emergência como fundamento da elaboração de leis, o que distorce o real sentido do direito penal, bem como sua contribuição para uma intervenção máxima desse ramo do direito na vida dos indivíduos, o que repercute na crise de intervenção mínima, tornando o direito penal expansivo e simbólico, muitas vezes motivados pela própria sociedade e pelo discurso midiático que clama pela emergência legislativa.

Quanto à metodologia, esta pesquisa utilizará o método dialético, visando o esclarecimento das causas para o fenômeno da crise de intervenção mínima e suas consequências no direito penal contemporâneo, bem como apontando a emergência como principal fundamento. Esta pesquisa é determinada como qualitativa, e serão utilizados o método bibliográfico, análise de conteúdo, e fontes secundárias, baseadas no entendimento de teóricos e autores a fim de embasar a elaboração deste artigo.

O artigo encontra-se segmentado em três seções, são elas: na primeira seção será abordado a emergência, seu conceito e origem, além de relacioná-la ao direto penal do inimigo e ao medo difundido pela mídia como causa de sua justificação. $\mathrm{Na}$ segunda seção, será apresentado o princípio da intervenção mínima, o jus puniendi e 
seus limites. Em seguida, na terceira seção, será elencado os resultados e discursões, onde se abordará os problemas da emergência e sua relação com a crise de intervenção mínima, bem como suas consequências. E por fim, será sugerido mecanismos para solucionar o problema e viabilizar a mudança nos conceitos estabelecidos pela sociedade moderna.

\section{DIREITO PENAL DE EMERGÊNCIA}

Emergência é tudo aquilo que foge do cotidiano, como explica Choukr (2002, p.01), é algo que "de forma repentina, surge de modo a desestabilizar o "status quo ante", colocando em xeque os padrões normais de comportamento e a consequente possibilidade de manutenção das estruturas". Assim, pode-se conceituar emergência como, algo fora do "padrão", utilizado para de forma célere solucionar aquilo que coloque em perigo o bem jurídico e a segurança social.

A cultura da emergência vem entrelaçada a uma ideia de risco, voltada para uma população amedrontada que convive diretamente com a criminalidade, tendo seu ápice com movimento Lei e Ordem (Law and Order), originado nos Estados Unidos, durante a década de 1990, em decorrência da reação social ao crescimento da criminalidade, onde a população buscava mecanismos para uma punição rápida dos infratores.

Diante disso, esclarece Sica (2002), que a emergência origina-se em uma sociedade acuada com a violência urbana, causando uma sensação de pânico, fundamentada e multiplicada por informações distorcidas da mídia, o que ocasiona um "sentimento de insegurança". Afirma ainda o autor, que o legislador quando cede ao clamor social, acaba por oferecer o direito penal como solução para todos os males sociais e consequentemente leva esse ramo do direito a um retrocesso.

A utilização de leis de emergência tornou-se corriqueira socialmente, o medo estabelecido pela criminalidade e difundido pela mídia bem como a ilusão de segurança 
trazida pela emergência, faz com que a vontade de solucionar a criminalidade se sobreponha aos conceitos básicos do direito. Nessa acepção, Hassamer (1993), considera lamentável que a sociedade, quando se sente ameaçada, priorize solucionar o problema, mesmo que, para isso, sejam violados os Direitos Fundamentais.

A respeito do emergêncialismo, Moccia (1999), conclui que ao se elaborar normas de cunho emergencial o uso do direito penal torna-se simbólico, oriundo de uma "presumida" política criminal eficaz, o que acaba por suplantar uma busca por soluções bem mais eficientes.

Nesse mesmo sentido, Franco (1994) afirma que o direito penal possui função claramente instrumental, considerando que o controle do Estado é simbólico, o direito penal não mais objetiva tutelar com eficácia bens jurídicos essenciais para a convivência harmônica, deseja apenas tranquilizar o cidadão e a opinião pública.

Destarte, pode-se entender que o direito penal de emergência é o reflexo da sociedade de risco, fundamentada no medo da violência e noticiada constantemente pela mídia, caracterizando o infrator como "inimigo" da ordem social, distorcendo o sentido do direito penal, que em regra, é subsidiário aos demais ramos do direito, e o torna popular por seu caráter sancionador, dando a população o que ela tanto almeja: se sentir segura, mesmo que seja uma sensação falsa e que isso tenha consequências jurídicas de difícil reparação.

\section{O INIMIGO COMO FUNDAMENTO DO DIREITO PENAL DE EMERGÊNCIA}

O Direito Penal é tido, como um instrumento político-social que visa a concretização dos preceitos estabelecidos constitucionalmente, desta feita, tem como objetivo proteger os bens e interesses sociais na busca de evitar a transgressão às normas, impondo penalidades à condutas que foram previamente incriminadas.

Ao analisar o contexto histórico da sociedade, vários grupos foram tidos como "inimigos sociais", não por terem cometido alguma conduta delituosa, mas 
simplesmente por serem diferentes, é o caso dos hereges e das bruxas, durante a Inquisição, ou mesmo a perseguição à judeus e à homossexuais, no estopim da Segunda Guerra, são exemplos dos considerados inimigos em momentos históricos distintos.

Contudo, grandes modificações atuam intensivamente no direito penal contemporâneo, o desenvolvimento tecnológico e a globalização contribuem para as desigualdades sociais, onde as pessoas tendem a ficar mais individualistas. A mídia infundada propaga cada vez mais, de forma dramática o aumento dos índices de criminalidade, causando pavor e insegurança nas pessoas surge daí, o "inimigo social", atualmente materializado na figura do delinquente.

Jakobs (2007, p. 25), para fundamentar sua teoria, toma como base os modelos filosóficos contratualistas, que entendem pela exclusão do infrator, "[...] $O$ delinquente infringe o contrato, de maneira que já não participa dos benefícios deste: a partir desse momento, já não vive com os demais dentro de uma relação jurídica." Dessa forma, existe uma dicotomia intitulada pelo jurista como, direito penal do cidadão e direito penal do inimigo.

Assim, conforme Jakobs (2007) pode-se classificar o inimigo como, todo aquele que persistentemente pratica delitos, e que por isso perde seu status de pessoa, onde será voltado para esse o direito penal do inimigo, pois suas condutas não podem serem vistas como "erro", uma vez que são reiteradas e consideradas como extremamente perigosas para a sociedade, o autor cita como exemplo o terrorista. Em contrapartida, aqueles que cometem crimes menores, esporadicamente, detém suas garantias e direitos e são amparados pelo direito penal do cidadão.

Diante disso, socialmente, as consequências trazidas pelo direito penal do inimigo se demonstram violadores do Estado Democrático de Direito. Meliá (2007), afirma que a utilização da ideia do inimigo gera um punitismo exacerbado, onde se acredita que a punição é o meio eficaz de solucionar a criminalidade, contudo o que se 
observa é o nascimento do simbolismo penal, o que torna as propostas dessa teoria ineficazes.

Meliá (2007) esclarece ainda que, o direito penal do inimigo fere a Constituição, uma vez que para essa teoria, o indivíduo perde seu status de pessoa detentora de direitos, onde na verdade ao invés de exclui-lo, a melhor forma de lidar com o inimigo é garantindo a eficácia do ordenamento jurídico, independente gravidade da conduta, devendo está presente os princípios e garantias do infrator.

Diante disso, resta nítido que como consequência do direito penal do inimigo, a tendência é um direito de emergência, vinculado a criminalização excessiva e uma rigorosidade das normas, tornando o direito penal empobrecido, fundado em simbolismo e expansionismo;

\section{O MEDO E A ATUAÇÃO DA MÍDIA NA CONSTRUÇÃO DO DIREITO PENAL DE EMERGÊNCIA}

O contexto contemporâneo em que estamos vivendo, é caracterizado pela globalização, em contrapartida esse avanço vai aos poucos se substituindo pelo sentimento de insegurança e de pavor que se instala generalizadamente por toda a população, isso decorre do aumento da criminalidade, originando o que se conhece como "Sociedade de Risco".

Diante disso, ressalta Bauman (2008, p. 12), que o risco está longe de exaurir-se uma vez que: "novos perigos são descobertos e anunciados quase diariamente, e não há como saber quantos mais, e de que tipos conseguiram escapar à nossa atenção (e à dos peritos!) - preparando-se para atacar sem aviso", o que reforça a ideia de uma sociedade moderna, temerosa e corroída pelo medo.

O alarme social dado aos riscos da criminalidade pela mídia na Era Moderna gera uma preocupação não justificada referente a segurança, que ocasionam 
constantes reclamações por uma maior eficácia e atuação do Estado no controle social, o que fomenta a denominada "cultura da emergência".

A comunicação passada pela mídia na intenção de convencer o telespectador e formar a opinião pública recebe o nome de discurso sensacionalista, definido por Vieira (2003) como uma linguagem caracterizada pela ausência de moderação, na busca de causar impacto, com o objetivo de envolver emocionalmente o telespectador, esse que fica incapaz de separar o que é real do que é sensacional.

O sensacionalismo, quando disseminado diariamente acaba por influenciar 0 processo de criminalização, retratando a violência como um objeto lucrativo, as notícias envolvendo a criminalidade tornam-se verdadeiras novelas melodramática, comercializadas com textos e ilustrações banalizando a violência e se tornam notícias tão corriqueiras que causam um efeito estarrecedor na população.

Vale salientar, que a maioria dos casos criminais transmitidos pela mídia, são cometidos por pessoas de baixa renda que vivem à margem social, que cometem crime de mínimo potencial ofensivo, contudo a forma como essas notícias são transmitidas causam um impacto tão grande na população, que passa a taxar o indivíduo, mesmo que por ventura seja julgado inocente, como criminoso.

Bauman (2005) classifica a sociedade pós-moderna como uma sociedade de consumo, e utiliza-se da expressão "lixo", para explicar como o ser humano é visto nessa sociedade, onde aquilo que já foi consumido é descartado, e o homem está sempre em busca do que é novo, dessa forma, o lixo deve ser rejeitado, excluído, a sociedade tende a qualquer custo encontrar um local próprio para depositá-lo.

Nesse sentido, aquilo que para nós é diferente não é aceitável e isso é claramente evidenciado quando se observam as prisões, lá é colocado o criminoso aquele que está à margem da sociedade, que é de baixa-renda, que é muitas vezes negro, que reside em favelas e que por isso deve ser taxado como o verdadeiro inimigo social. 
Diante dessa análise, é perceptível que a mídia detém um forte poder de convencimento e de formação de opinião pública, em se tratando de questões criminais, a imprensa mostra-se ainda mais incisiva, uma vez que atua no sentimento e abalo psicológico da população, que já tomada pelo medo não vê saída a não ser provocar o legislador a posicionar-se de forma rápida a fim de combater a violência.

\section{PRINCÍPIO DA INTERVENÇÃO MÍNIMA DO DIREITO PENAL}

\subsection{JUS PUNIENDI: O PODER DE PUNIR DO ESTADO}

O direito penal de acordo com Greco (2011) divide-se em objetivo que é o conjunto de normas penais, e subjetivo que é o jus puniendi, o poder de punir, titular do Estado, assim o poder de punir expressa a faculdade do Estado em elaborar e executar suas leis.

Greco (2011), explica que o jus puniendi pode se legitimar como o direito conferido ao Estado de elaborar normas por meio do poder legislativo, que regulam a convivência dentro de uma sociedade (sentido objetivo), e pelo poder judiciário de executar suas normas proferindo decisões criminais que tornam um conduta passível de punição (sentido subjetivo), disso resta presente a estrita relação de continuidade entre a política criminal e o jus puniendi.

Não obstante, deve-se compreender que existe muito além de um direito de punir conferido ao Estado, mas em decorrência de seu vínculo a princípios constitucionais, tem-se o reconhecimento de um dever de punir diante de uma conduta delituosa, permitindo o Estado sancionar o crime, contudo garantindo a proporcionalidade da pena a conduta do agente e obedecendo a Constituição.

No momento em que surgem condutas delituosas, o detentor do poder -dever de punir, não deve se abstrair em manifesta-lo, uma vez que faz-se necessário garantir o bem-estar e a ordem social, nesse sentido, "A aplicação do Direito Penal e a execução 
de sanções decorrentes de sua aplicação concreta constituem, portanto, mais que um direito, um poder do Estado, poder que não pode deixar de atuar [...]" (REALE JUNIOR, 2013, p.15).

Porém, ao analisar o jus puniendi e sua manifestação no sistema jurídico-penal, o que se observa é a arbitrariedade e o autoritarismo do Estado, desde o momento em que uma lei é criada até sua execução, o sistema político é movido por uma sociedade amedrontada pelo crescimento da criminalidade, onde o direito penal ganha populismo e passa a ser a principal chave de "acalmar" a população e causar a sensação de presteza na punição do agente infrator.

\subsection{LIMITES AO JUS PUNIENDI}

Diante da interferência do jus puniendi no direito penal, para manutenção do garantismo e a extinção da arbitrariedade na manifestação desse poder-dever, é de suma importância a existência de um "controle", com isso, existem princípios que funcionam como limitadores do Estado na aplicação da lei penal.

Dentre esses princípios, pode-se destacar o princípio da legalidade, o princípio da ofensividade, o princípio da proporcionalidade e o princípio da intervenção mínima, este que será abordado de uma forma mais aprofundada nesta pesquisa.

O princípio da legalidade ou reserva legal é o limite estipulado pela lei à aplicação arbitraria do direito penal, para Greco (2011, p. 17), "A lei, portanto, é a bandeira maior do Direito Penal. Sem ela, proibindo ou impondo condutas, tudo é permitido". Diante disso, pode-se afirmar que não há crime sem que haja lei que o defina como tal, mesmo que a conduta do agente seja reprovável socialmente se ela não for tipificada não há o que se falar em punição.

Assim, o princípio da reserva legal funciona como uma garantia constitucional individual, restringindo as condutas ilícitas àquelas que forem anteriormente tipificadas. 
Não há crime sem ameaça concreta e lesão grave ao bem jurídico protegido pelo direito penal -nullum crimen sine injuria.

O princípio da ofensividade, determina que apenas serão tipificados os atos que mostrarem perigo efetivo de lesão a um bem jurídico penalmente tutelado, Bitencourt (2013, p. 61), nesse sentido, afirma que "são inconstitucionais todos os chamados crimes de perigo abstratos", pois só existe infração penal quando há um efetivo, real e concreto perigo de lesão a um bem jurídico protegido pela norma penal.

Há, portanto, um controle no tocante a sancionar apenas aquilo que cause dano concreto a bens jurídicos de interesse social, salientando-se quando tais atos mantêm seus efeitos na esfera de interesse individual não é punível, pois uma autolesão, por exemplo, embora seja típico, gera efeitos apenas para o agente não possuindo relevante importância para a sociedade.

Os resquícios da proporcionalidade podem ser observados em 1.700 a.C, na Lei do Talião, que embora a expressão "olho por olho e dente por dente" mostre-se em primeiro plano como uma desumanidade, foi um marco positivo no direito uma vez que estabelece a igualdade e a proporcionalidade da punição ao ato praticado.

O princípio da proporcionalidade é uma consequência do princípio da legalidade, e estabelece que a pena deve ser proporcional à conduta do agente, dessa forma o referido princípio remete a ideia de adequação, de razoabilidade, voltado não para a coletividade, mas para o indivíduo indo em concordância com a dignidade da pessoa humana.

Segundo Battaglini apud Marques, "o condenado precisa sentir que existe um equilíbrio entre o dano que produziu e o castigo que a sociedade lhe inflige, pois de outra forma o culpado se transformaria em vítima, e o credor em devedor". (MARQUES, 2006, p.105).

Nessa perspectiva, Bonavides (2006, p. 434) aborda que:

Em nosso ordenamento constitucional não deve a proporcionalidade permanecer encoberta. Em se tratando de princípio vivo, elástico, 
prestante, protege ele o cidadão contra os excessos do Estado e serve de escudo à defesa dos direitos e liberdades constitucionais. De tal sorte que urge, quanto antes, extraí-lo da doutrina, da reflexão, dos próprios fundamentos da Constituição, em ordem a introduzi-lo, com todo o vigor, no uso jurisprudencial.

Assim, como os demais princípios limitadores do jus puniendi, o princípio da proporcionalidade, evita a arbitrariedade do Estado na aplicação excessiva e desonesta da pena atribuída ao indivíduo, correspondendo essa pena ao grau de gravidade da conduta exercida o que viabiliza e garante o respeito aos direitos fundamentais.

Nesse patamar, com o desenvolvimento da sociedade e das concepções de política, surge uma preocupação em estabelecer um direito penal regrado aos preceitos constitucionais, respeitando os direitos mínimos sociais e os princípios basilares advindos da Constituição Federal.

Diante disso, muitos pensadores políticos como Montesquieu (1962) e Beccaria (1997), buscavam uma forma de limitar a intervenção do Estado no tocante à liberdade individual com a intenção de substituir as sanções penais por meios alternativos, em decorrência desse posicionamento surge o Princípio da Intervenção Mínima como o fundamento do direito penal mínimo que limita o poder de criar delitos. Nesse sentido, "[...]Surgia o princípio da necessidade, ou da intervenção mínima, preconizando que só se legitima a criminalização de um fato se a mesma constitui meio necessário para a proteção de um determinado bem jurídico" (LUISI, 2002, p.39).

O princípio da intervenção mínima se fundamenta na característica de ultima ratio, limitando o Estado a aplicar o direito penal nas hipóteses de falha dos demais ramos do direito, quando a lesão provocada ao bem jurídico for considerada grave.

Bitencourt (2013), conceitua tal princípio como limitador do poder incriminador do Estado, só ocorrendo a criminalização de conduta se o bem jurídico violado for importante, salienta ainda, tal autor que no instante em que medidas alternativas como as civis ou administrativas forem empregadas e conseguirem restabelecer a ordem jurídica, a aplicação do direito penal torna-se inadequada. 
A Revolução da Burguesia, ocorrida durante o período absolutista, traz os ideais de humanização da pena e a concepção de que a solução para a criminalidade não é voltada unicamente para a elaboração exacerbada de normas, pelo contrário, como estabelece Montesquieu (1962, p.109) "quando um povo é virtuoso bastam poucas penas".

Porém, durante o século XIX, houve uma maior interferência penal, o legislador passou a elaborar normas de forma desmedida, oriundas principalmente pelo sistema penal em que a sociedade se enquadra, desvirtuando o sentido da intervenção mínima e tornando o direito penal prima ratio, como única forma de coibir lesões a ordem social acabando por ocasionar uma severidade maior de normas e um número exagerado de leis.

Foppel (2004), afirma que além de sua finalidade convencional de sancionar um indivíduo, a pena detém a função de incutir nas pessoas uma aparência de tranquilidade e segurança, onde o Estado se vale da pena como forma de iludir os cidadãos com a falsa imagem de austeridade, de força e de poder, enquanto que a criminalidade continua crescendo.

Pode-se afirmar que em decorrência do princípio da intervenção mínima, surgem dois elementos característicos do Estado Penal, são eles a subsidiariedade, que dá ao direito penal o entendimento de ultima ratio e a fragmentariedade, que torna as leis penais seletivas a importância do bem lesado.

Destarte, compreende-se por intervenção mínima, o núcleo que orienta a política criminal, reduzindo a interferência do Estado e priorizando os direitos fundamentais estabelecidos pelo estado democrático de direito, colocando em fim a postura autoritarista do direito penal e se sobrepondo a política criminal de emergência.

Segundo Damásio de Jesus (2013 p.52), "A criação de tipos delituosos deve obedecer à imprescindibilidade, só devendo intervir o Estado, por intermédio do Direito Penal, quando os outros ramos do direito não conseguirem prevenir a conduta ilícita", 
por isso o legislador deve encontrar outro meio para resolver litígios que não seja a norma penal.

Resta assim, a compreensão de que outros ramos do direito podem ser suficientes para tutelar um bem jurídico, sem a necessidade da constante interferência Penal, existem casos em que a reparação, seja cível ou administrativa, supre a sanção penal.

Nesse sentido, Santiago (2007), aborda que o direito penal deixa de ser necessário quando a proteção da sociedade puder ser obtida por outros meios menos lesivos aos direitos sociais.

À vista disso, o princípio da subsidiariedade pode ser entendido como a ultima ratio do direito penal, limitando as normas incriminadoras criadas de forma desnecessária, utilizando a lei penal em último recurso apenas na falta de demais meios menos lesivos.

Contudo, diante do desenvolvimento dos meios de comunicação o sistema penal torna-se expansionista, que se resume na interferência das leis penais em casos de perigo abstrato, que por vez violam a subsidiariedade ocasionando uma banalização e o uso desmedido do direito penal.

O direito penal não tutela todos os bens jurídicos, apenas os de maior relevância social como a vida, a liberdade, a segurança. Disso surge a característica da fragmentariedade, quando existe o que Damásio de Jesus (2013, p.52), chama de "fragmento dos interesses jurídicos".

O princípio da fragmentariedade é um desdobramento do princípio da intervenção mínima, tal princípio limita o objeto de tutela o qual o direito penal deve proteger, dessa forma, apenas será punido penalmente aquele que violar um bem jurídico considerado indispensável para a sociedade.

Bitencourt (2013, p. 55), a respeito do caráter fragmentário, aborda que "o direito penal não deve sancionar todas as condutas lesivas dos bens jurídicos, mas tão 
somente aquelas condutas mais graves e mais perigosas praticadas contra bens mais relevantes"

Essa seletividade decorrente do direito penal fragmentário se justifica pelo grau de violação do direito penal, por ser o ramo do direito tido como sancionador e violento que abala as esferas individuais do cidadão.

Destarte, a fragmentariedade do direito penal limita o Estado no tocante à tutela de bens jurídicos indispensáveis para manutenção da ordem jurídica, porém com a elaboração de legislação simbólica, decorrente da pressão social, entram em choque com os objetivos do direito penal que é a adequação dos princípios e o respeito à Constituição visando um direito punitivo garantista.

\section{DIREITO PENAL DE EMERGÊNCIA E SUA INFLUÊNCIA PARA O SURGIMENTO DA CRISE DE INTERVENÇÃO MÍNIMA DO DIREITO PENAL}

\subsection{A EMERGÊNCIA E SEUS REFLEXOS NO DIREITO PENAL}

Em decorrência da intensa aplicação do direito penal, motivada pelo sensacionalismo midiático e o clamor público para a intervenção do Estado no tocante ao controle da criminalidade, o que se observa nas políticas criminais do Brasil é o desvirtuamento do direito penal de sua característica de subsidiariedade (ultima ratio) e fragmentariedade, refletida em uma desnecessária criminalização de condutas consideradas irrelevantes para o direito penal.

O direito penal atualmente passa a tutelar bens jurídicos não pela sua importância, mas pelo que a sociedade considera como indispensável, diante disso o sistema penal é alvo de discussões acerca de sua constitucionalidade, uma vez que ao criminalizar mais condutas e tornar o direito penal mais repressor coloca-se em xeque 0 garantismo instituído pelo direito penal. 
O que se identifica na ciência criminal contemporânea, é o emprego do "direito penal de emergência", que deixa de ser política de exceção, e ingressa no ordenamento jurídico como algo natural em decorrência de seu uso corriqueiro, por ser uma resposta rápida aos anseios sociais, o que tem como consequência a hipertrofia do direito penal.

Sica (2002), explica que a hipertrofia penal é decorrente do emocionalismo e da aplicação da emergência para controlar o ânimo social, o que torna o direito penal autoritário, expansivo e demagogo, distanciando-se da racionalidade e indo de encontro a eficiência e finalidade do direito penal.

Assim, a emergência nada mais é, do que a tipificação de condutas criminosas pelo legislador, distanciando o direito penal de sua finalidade em decorrência da manipulação da mídia e da intervenção emocional da sociedade.

Choukr (2002) atribui a emergência um sentido político, ao afirmar que as manifestações ideológicas colocam determinadas situações como incontroláveis, de maneira que se justifique o incremento dessa característica no ordenamento jurídico.

Diante disso, ocorre a ampliação da criminalização para proteção de interesses particulares, e onde as normas casuísticas causam a sensação de "falsa de segurança "e de um estado atuante, o que em tese fere a fragmentariedade do direito penal. Moccia (1999 p. 74-75.), por sua vez, atribui a simbologia das leis ao movimento emergencialista, quando afirma que:

O emergencialismo, em outras palavras, gerou o uso simbólico do direito penal em nome de uma presumida política criminal e eficiência, que acabou por suplantar a busca de soluções de política social geral bem mais eficiente.

Nesse interim, Queiroz (2008. p. 51 - 53), aborda o direito simbólico como um meio de descrença do direito penal uma vez que: 
Um direito penal simbólico carece de toda legitimidade, pois manipula o medo ao delito e à insegurança, reage com um rigor desnecessário e desproporcionado e se preocupa exclusivamente com certos delitos e infratores, introduz um sem fim de disposições excepcionais, a despeito de sua ineficácia ou impossível cumprimento, a médio prazo, desacredita o próprio ordenamento, minando o poder intimatório de suas prescrições.

Os reflexos da emergência podem ser observados em algumas leis, como a Lei no 8.072/90, de 15 de julho de 1990 (Lei dos crimes hediondos), que em 1994, sofreu uma alteração e incluiu o homicídio premeditado ao rol de crimes hediondos, em decorrência do assassinato da atriz Daniella Perez, pela grande repercussão midiática referente ao homicídio da atriz e filha da escritora Glória Perez.

A Lei 11. 340/2006 (Lei Maria da Penha), que surgiu depois da luta de Maria da Penha, vítima de violência doméstica, para a punição de seu agressor. O caso Maria da Penha, só foi observado depois da grande repercussão, inclusive internacionalmente, em virtude da inercia do Brasil no tocante a casos como esse, foi necessário recorrer a Corte de Direitos Humanos.

Recentemente, outra lei promulgada rapidamente pelo fato da vítima do crime ser uma atriz famosa brasileira, foi a Lei $n^{\circ} 12.737 / 2012$, popularmente conhecida como Lei Carolina Dieckmann, em virtude de suas fotos íntimas terem sido divulgadas na internet, tal lei pune os crimes cometidos na internet, porém é muito criticada, uma vez que só criminaliza condutas que violem mecanismos de segurança.

Outro grande marco da emergência foi a inclusão ao Feminicídio, como qualificadora do artigo 121, do Código Penal, que trata de crime doloso contra a vida praticado contra vítima mulher, por razão da condição de ser do sexo feminino.

Faz-se importante saber que embora existam exemplos concretos da influência da emergência provocada por interferência da sociedade, nem sempre o Estado se manifesta em elaborar lei, ele se mantém inerte, até que surja um fato amplamente divulgado e que tome proporções incontroláveis, porém o que se observa é que ao agir, 
por ser de forma rápida, grande parte das leis são meramente simbólicas, algumas bem rígidas e punitivistas, elaboradas apenas para acalmar o ânimo social.

Em síntese, o resultado da legislação de emergência são as crises enfrentadas pelo ordenamento jurídico, em sua maioria no direito penal, que perde sua credibilidade e eficácia, além de suas consequências se voltarem grande parte para problemas sociais, como o aumento da criminalidade e a superlotação das penitenciárias.

\subsection{A CRISE DE INTERVENÇÃo MÍNIMA COMO CONSEQUÊNCIA DA EMERGÊNCIA}

É notório que pelo princípio da fragmentariedade, o direito penal é utilizado para salvaguardar os bens jurídicos que de acordo com Prado (2014. p. 115) são, "imprescindíveis à coexistência pacífica dos homens e que não podem ser eficazmente protegidos de forma menos gravosa", por ser o direito penal um ramo violento do direito, faz-se necessária uma análise de sua incidência, para que seja utilizado o mínimo possível daí a necessidade do princípio da intervenção mínima.

Contudo, ao se observar o contexto social atual, percebe-se que o princípio da intervenção mínima encontra-se envolto a uma crise, onde o expansionismo do direito penal torna-se evidente, novos tipos penais são instituídos, os existentes são incrementados, o processo é reinterpretado para atender as necessidades e novos bens jurídicos são tutelados para alcança o surgimento de novos "riscos sociais".

Destarte, a abrangência do ordenamento jurídico penal, inviabiliza a previsão das garantias jurídicas e de um direito tido como "mínimo", uma vez que a característica da sociedade contemporânea do risco é a máxima intervenção punitiva.

A crise de intervenção mínima é decorrente de vários fatores, dentre eles a inoperância do Estado na elaboração de políticas sociais, que visem uma alternativa para a diminuição da violência, e um aumento dos números de condutas incriminadas voltadas unicamente para a punição severa dos agressores (inimigos sociais), 
idealizados pela mídia e pelo medo social, esse número excessivo de normas tornam o direito penal ineficaz.

Karam, (1991, p. 200-201), aborda a influência do medo propagado pela mídia como fonte da descrença do direito penal onde:

Esta publicidade enganosa cria o fantasma da criminalidade, para em seguida, 'vender' a ideia da intervenção do sistema penal, como a alternativa única, como a forma de se conseguir a tão almejada segurança, fazendo crer que, com a reação punitiva, todos os problemas estarão solucionados.

Em decorrência da intervenção do direito penal, ver-se como intensificadora da crise uma grande quantidade de leis desnecessárias, e sem eficácias que tumultuam o ordenamento jurídico penal e o poder judiciário fica afogado em inúmeros processos e leis penais de cunho simbólico.

Diante disso, a interferência da emoção social e da mídia para a criação de soluções rápidas e a utilização do direito penal de emergência como meio para efetiválas, entram em colisão com o princípio da intervenção mínima, originando-se a crise jurídica e o populismo penal, aliena a população que conforme Sanchéz (2002), se mostra contra o minimalismo.

$\mathrm{Na}$ atual conjectura do ordenamento jurídico, para solucionar a crise existente faz-se necessária a concretização estabelecida pelo princípio da intervenção mínima, desenvolvendo uma descriminalização de condutas, tipificando apenas aquilo que é indispensável para a manutenção da paz pública, removendo do direito penal a característica de prima ratio e de simbolismo.

Assim, o que se observa como consequência do emergencialismo, é a crise de intervenção mínima que traz consigo vários outros problemas no ordenamento jurídico, como a hiperinflação legislativa, o simbolismo e o expansionismo do direito penal.

A hiperinflação legislativa atualmente é o assunto principal das críticas ao sistema penal, pois o poder coercitivo do Estado é reduzido no instante em que há uma 
criação excessiva e contínua de tipos penais que não são satisfatórios a proteção dos bens jurídicos.

Resta evidente, que tornou-se cada vez mais comum a utilização das leis penais objetivando equilibrar as relações sociais, econômicas e políticas e, também, atender à pressão da sociedade, contudo na grande maioria das vezes, o legislador, não observa todas as circunstâncias que possam prejudicar a eficácia das leis penais e que interferem de forma significativa na real função que o direito penal deveria cumprir, desta forma, vem fomentando o fenômeno da criminalização exacerbada de normas.

O uso desenfreado do direito penal para criminalizar condutas, pode ser observado em quaisquer governos ou épocas, e grandes autores como Montesquieu (1962), já condenava o uso excessivo de leis, pois para tal autor, o legislador ordenando e proibindo a população torna o povo infeliz.

O fenômeno da Hiperinflação é consequência da legislação emergencial, pois as maiorias das normas respondem de imediato as necessidades sociais, estabelecidas pela "sociedade de risco" ou "sociedade do medo", o que ocasiona uma intervenção máxima na vida social e um questionamento de eficácia de tal medida, "se o Direito penal de um Estado social só se legitima na medida em que protege a sociedade, perderá sua justificação caso a intervenção demonstre-se inútil por ser incapaz de evitar delitos". (SANTIAGO, 2007, p. 92).

Assim, quanto mais legiferação penal e quanto mais severa é a penalidade, mais cerceadas são as garantias individuais, mais normas são infringidas e mais alto fica o número de reincidência, no lugar de solucionar a criminalidade intensifica a crise do ordenamento jurídico.

O expansionismo penal é reflexo da sociedade de risco moderna, onde novos bem jurídicos emergem do desenvolvimento tecnológico, que passam a ser legitimados, alterando significativamente o sentido do direito penal.

A aplicação do jus puniendi dar-se pelo surgimento de atos criminalizados, e da tendência do legislador moderno em solucionar os problemas sociais mediante 
tipificação penal, o que viabiliza o afastamento do direito penal de seus princípios limitadores e fundamentais, que como abordado anteriormente deixa de ser utilizado de forma suplementar.

A expansão do direito penal pode ser tida como consequência da crise de intervenção mínima, onde o direito penal é utilizado como ultima ratio, ocorrendo a instrumentalização do direito penal, onde passa a deixar mais evidente seu caráter sancionador, intitulado por Sanchéz (2002) como "administrativização do direito penal".

Queiroz (2005) faz uma crítica à intervenção do Estado, onde esse não pode intervir violentamente na vida dos cidadãos, tendo em vista que para tal autor o direito penal é um ramo violento, com o pretexto de infundir o sentimento de segurança, uma vez que a intervenção penal só pode ter lugar em situação de absoluta necessidade e adequação.

É relevante compreender, que com o expansionismo penal, o que se observa é a presença da chamada terceira velocidade do direito penal, fundamentada por Sanchéz (2002), que a define pela existência de um rigor que deixa de lado os princípios e garantias básicas estabelecidas pela constituição, que por tão incidental na vida dos cidadãos se reflete em um direito penal do inimigo.

Dessa forma, a terceira velocidade do direito penal é a expansão penal, esta que se encontra vinculada a um sistema criminal que pune inimigos, caracterizado pela desproporcionalidade e rigidez das penas, que são as principais consequências dessa política.

Diante Disso, o que se pode detectar do expansionismo é a busca do Estado em Punir o infrator a qualquer custo, com o intuito de demonstrar sua atuação e transportar para a sociedade a sensação de que o problema está resolvido, contudo tal desdobramento se mostra ineficaz e a criminalidade continua acordada e quem mais sofre é o sistema penal por completo que está corroído em crises de legitimidade.

A Expansão penal, caracterizada pela intervenção máxima do Estado, deve ser evitada, os governantes tem obrigação de encontrar meios alternativos, senão o direito 
penal, devendo adotar métodos que conciliem as exigências da sociedade moderna pelo controle da criminalidade, com um direito penal garantista, estabelecido pela constituição, evitando-se um punitivismo simbólico.

Com a Crise de intervenção mínima, oriunda de uma política emergencialista, observa-se um direito penal expansivo (rígido), composto por uma grade quantidade de leis, muitas vezes desnecessárias (hiperinflação), que possuem significado totalmente simbólico.

Desta feita, o direito penal simbólico manifesta-se da necessidade de urgência, onde o Estado aplica de forma irregular o direito penal, simulando uma atuação efetiva de combate à criminalidade. Segundo Ricardo Dip (2002, p. 221), o direito penal simbólico, "[...] promete a paz pública com a só visão de letrinhas imperatórias estampadas ritualmente na imprensa oficial".

Entretanto, a edição descontrolada de leis, e a busca por um punitivismo rígido, se mostram perigosos para o ordenamento, uma vez que a tendência é que essas leis fiquem apenas no plano abstrato, intensificando o aumento do número de leis editadas, e ainda assim, uma não efetiva diminuição da violência o que, por conseguinte, torna o direito penal sem credibilidade e ineficaz.

O perigo do simbolismo é explorado por Ricardo Dip (2002), quando afirma que o crime não é quantitativo, não será resolvido com um número exacerbado de leis, mas será controlado se as leis já existentes forem eficazes.

Assim, o simbolismo penal atinge seu objetivo, não apontando soluções, mas servindo como forma paliativa, tranquilizando a sociedade por meio de respostas céleres e levando a falência do direito penal.

Destarte, pode-se considerar que o ordenamento jurídico penal brasileiro é corroído lentamente por políticas-públicas voltadas para a emergência, que distorcem o real objetivo do direito penal, tornando-o máximo, o que viabiliza o surgimento da crise denominada de crise de intervenção mínima. 
Porém, o Estado tem se beneficiado de seu dever de jus puniendi, como forma de transmitir à sociedade, a ideia de que o Direito Penal é a solução ideal para a violência, sem deixar claro que esta é tão somente resultado da inercia na adoção de políticas alternativas que seriam muito mais eficazes para a solução desse problema, revelando a omissão Estatal.

O Estado, então, passa a adotar a emergência da lei, por ser um meio rápido de resposta à sociedade que amedrontada, pela figura do criminoso, o inimigo social, cobra por soluções eficazes, que ao contrário, corrobora para a crise de intervenção mínima, que nasce em decorrência da "sociedade do medo" (risco), como é chamada a sociedade moderna, que emerge em violência propagada diariamente pela mídia.

O que se observa como consequência dessa crise, é uma expansão do direito penal, na edição de leis novas ou reinterpretação de leis existente, que propagam o simbolismo, e a hiperinflação legislativa, tornando o direito penal rígido e punitivista o que distorce a sua função e o torna desacreditado.

Pode-se observar os efeitos da emergência, nas já citadas Leis de Crimes Hediondos, Lei Carolina Diekmann, percebe-se a emergência na integração do feminicídio ao ordenamento jurídico, na Lei Maria da Penha, na Lei do Bullying, dentre outras, que passaram a ser tutelados pelo direito penal, depois da grande repercussão dada pela mídia, que incentiva a sociedade a cobrar atitudes do Estado, este que o faz para se mostrar ativo, com intenções de se promover politicamente.

Resta salientar, também, que embora a crise de intervenção exista, e que como nos exemplos citados é possível perceber o caráter emergencial da tutela penal, o Estado nem sempre reponde à sociedade, apenas em casos amplamente divulgados e que causem profundo abalo social, mesmo que a mídia transmita e a população reivindique, o legislador deixa de fazê-lo prova disso, é a discursão acerca da maioridade penal, dos crimes de corrupção, que estão cada vez mais frequentes, e dos crimes de homofobia. 
A solução para tais controvérsias, seria a busca por um direito penal garantista, voltado a preceitos constitucionais, que priorizem a intervenção mínima do Estado, e o fortalecimento do direito penal como ramo suplementar, quando a população e a mídia se derem conta de que rigor e punitivismo não combatem a violência, pelo contrário só aumenta, e quando o legislador agir de forma racional e não no intuito de se promover politicamente, utilizando de um controle penal mascarado, esse problema social será controlado. A resposta está na implementação de políticas públicas sociais diversas, que identifiquem a violência em sua raiz, pois do que adianta punir o criminoso, sem observar os caminhos que o levaram a delinquir.

\section{CONSIDERAÇÕES FINAIS}

O contexto atual da sociedade e o grande desenvolvimento tecnológico e midiático apresentam um denominado "populismo" do Direito Penal, caraterizado por uma população que reivindica por soluções rápidas para os conflitos sociais, gerando o que se denomina: legislação de emergência.

Ao se abordar o direito penal de emergência e a aplicação do poder de punir do Estado, fica evidente a existência de um sistema penal irracional, voltado a uma intervenção máxima do Estado que se utiliza de leis emergenciais para tranquilizar a sociedade e se mostrar atuante.

O que vem acontecendo na atualidade com o ordenamento jurídico, é de relevante preocupação, pois o pressuposto constitucional básico do Estado Democrático de Direito e o princípio da intervenção mínima, vem sendo substituídos pela máxima intervenção social. O Direito Penal, cuja utilização punitiva deveria ficar restrita somente aos fatos de grande gravidade e os de maior intensidade, tem sido desvirtuado pelo grande número de leis elaboradas por clamor, além de está enfrentando uma severa crise jurídica. 
A incriminação de condutas motivadas por clamor social, somada a influência dos meios de comunicação, que espalham o medo por meio de notícias infundadas de aumento da criminalidade, são suficientes para mitigar os princípios constitucionais necessários para limitar a intervenção do Estado e tornar o direito penal racional e garantivista.

É necessária a compreensão de que a criação de leis não soluciona a criminalidade, pelo contrário a intensifica, pois no instante em que condutas, outrora tidas como insignificantes, tornam-se abrangidas pelo direito penal e novos tipos penais são incorporados ao ordenamento jurídico, a tendência é que este se torne rigoroso e expansivo, contudo as respostas são adversas ao que se espera num instante em que a lei existe, a conduta é tipificada, porém a criminalidade não foi reduzida

Outro ponto relevante é que além dos reclames sociais e do pânico transmitido pela mídia, o Estado utilizar-se da lei como forma promocional, a fim de atender a interesses políticos e não sociais, ou seja, quando leis são criadas e aplicadas após a ocorrência de fatos de grande difusão social, com a intenção de garantir politicamente, dando a que a população o que ela almeja: punição ao extremo, isso se torna o ápice para a hipertrofia penal.

Esta pesquisa demonstrou que uma política social voltada ao emergêncialismo e a criação de leis fundamentadas em sensacionalismo midiático, emocionalismo social e opções políticas, tornam o direito penal autoritário, revestido em tendências expansionistas e simbólicas, contribuem para uma involução do direito penal, aumentando-se a aplicação do punitivismo e reduzindo-se a incidência de garantias e princípios básicos, resultando em um direito penal contrário aos objetivos de um Estado Democrático de Direito.

Conclui-se, portanto, que a crise de intervenção mínima enfrentada pelo direito penal brasileiro, é decorrente da legislação de emergência ,onde o legislador não busca combater a violência de forma estrutural, não adere ao cerne do problema, a criminalidade torna-se fruto de uma política individualista, voltada para a exclusão do 
diferente, sendo mais "prudente" elaborar leis penais emergenciais totalmente simbólicas e ineficazes, que não servem para nada senão inflacionar o ordenamento jurídico penal, com o objetivo "acalmar" a sociedade e mostrar que está agindo, do que elaborar políticas sociais eficazes que priorizem os direitos e garantias, que trabalhe na inclusão dos indivíduos.

\section{REFERÊNCIAS}

BAUMAN Zygmunt. Vidas desperdiçadas. Tradução de Carlos Medeiros. Rio de Janeiro: Zahar, 2005.

Zahar, 2008.

Medo líquido. Tradução de Carlos Alberto Medeiros. Rio de Janeiro: Jorge

BECCARIA, Cesare. Dos delitos e das penas. Tradução de De Flório de angelis. Bauru: Edipro, 1997.

BITENCOURT, Cezar Roberto. Tratado de direito penal: parte geral, v.1. 19. ed. Ver e atual. São Paulo: Saraiva, 2013.

BONAVIDES, Paulo. Curso de Direito Constitucional. 18. ed. São Paulo: Malheiros, 2006.

BRASIL, Lei no 12.737 de 30 de novembro de 2012. Dispõe sobre a tipificação criminal de delitos informáticos; altera o Decreto-Lei № 2.848, de 7 de dezembro de 1940 - Código Penal; e dá outras providências. Disponível em:

<http://www.planalto.gov.br/ccivil_03/leis/LEIS_2001/L10257.htm>. Acesso em 21 nov. 2017.

, Lei 11.340 de 7 de agosto de 2006. Cria mecanismos para coibir a violência doméstica e familiar contra a mulher, nos termos do § 8ㅇ do art. 226 da Constituição Federal, da Convenção sobre a Eliminação de Todas as Formas de Discriminação contra as Mulheres e da Convenção Interamericana para Prevenir, Punir e Erradicar a Violência contra a Mulher; dispõe sobre a criação dos Juizados de Violência Doméstica e Familiar contra a Mulher; altera o Código de Processo Penal, o Código Penal e a Lei de Execução Penal; e dá outras providências. Disponível em: 
< http://www.planalto.gov.br/ccivil_03/_ato2004-2006/2006/lei//11340.htm>. Acesso em 21 nov. 2017.

. Lei 8.930 de 6 de setembro de 1994. Dá nova redação ao art. 1ํ da Lei no 8.072, de 25 de julho de 1990, que dispõe sobre os crimes hediondos, nos termos do art. 5o, inciso XLIII, da Constituição Federal, e determina outras providências.

Disponível em: < http://www.planalto.gov.br/ccivil_03/leis/L8930.htm>.Acesso em 21 nov.2017.

. Lei 13.104 de 9 de março de 2015. Altera o art. 121 do Decreto-Lei no 2.848, de 7 de dezembro de 1940 - Código Penal, para prever o feminicídio como circunstância qualificadora do crime de homicídio, e o art. 1o da Lei oㅡ 8.072, de 25 de julho de 1990, para incluir o feminicídio no rol dos crimes hediondos. Disponível em :< http://www.planalto.gov.br/ccivil_03/_Ato2015-2018/2015/lei/L13104.htm>. Acesso em 21 nov.2017.

CHOUKR, Fauzi Hassan. Processo Penal de Emergência. Rio de Janeiro: Lumen Juris, 2002.

DIP, Ricardo, Volney Corrêa Leite de Moraes Júnior. Crime e castigo: reflexões politicamente incorretas. Campinas: Millenium, 2002,

FRANCO, Alberto Silva. Crimes Hediondos, 3. ed, São Paulo: Revista dos Tribunais, 1994.

HIRECHE, Gamil Foppel el. A função da Pena na visão de Claus Roxin. Rio de Janeiro: Forense, 2004.

JAKOBS, Günter; MELIÁ, Cancio. Direito Penal do Inimigo: noções e críticas. Organização e tradução de André Luis Callegari e Nereu José Giacomolli. Porto Alegre: Livraria do Advogado, 2007.

JESUS, Damásio. Direito Penal :Parte Geral, v.1. 34. ed. São Paulo: Saraiva, 2013.

KARAM, Maria Lúcia. De crimes, penas e fantasias. Rio de Janeiro: Luam, 1991.

LUISI, Luiz. Os princípios constitucionais penais. 2. ed. Porto Alegre: Sergio Antônio Fabris, 2002.

MARQUES, José Frederico. Tratado de Direito Penal. . vol. 1. 1. ed. Campinas: Bookseller, 1997. 
MOCCIA, Sergio. Emergência e Defesa dos Direitos Fundamentais. In: Revista Brasileira de Ciências Criminais. Ano 7, n. 25. São Paulo: Revista dos Tribunais,1999.

MONTESQUIEU, Charles-Louis de Secondat. Do espírito das leis. Tradução de F. H. Cardoso e L.M. Rodriguez. São Paulo, 1962.

QUEIROZ, Paulo. Funções do Direito Penal: Legitimação versus Deslegitimação do Sistema Penal. 3. ed. rev. e atual. São Paulo: Editora Revista dos Tribunais, 2008. REALE JR, Miguel. Instituições de Direito PENAL: Parte Geral. 4. ed. Rio de Janeiro : Forense,2013

ROGERIO, Greco. Curso de Direito Penal: Parte Geral. v.1. 13. ed. Rio de Janeiro: IMPETRUS,2011.

SANTIAGO, Mir Puig. Direito penal: fundamentos e teoria do delito. Trad. Claudia Viana Gacia, José Carlos Nobre Porciúncula Neto. São Paulo: RT, 2007.

SICA, Leonardo. Direito Penal de Emergência e Alternativas à prisão. São Paulo: Revista dos Tribunais, 2002.

SILVA SÁNCHEZ, Jesús María. A expansão do Direito Penal. Trad. Luiz Otávio de Oliveira Rocha. São Paulo: RT, 2002.

VIEIRA, Ana Lúcia Menezes. Processo Penal e Mídia. São Paulo: Revista dos Tribunais, 2003.

WINFRIED, Hassemer. Três temas de Direito penal. Porto Alegre: Publicações da Fundação Escola Superior do Ministério Público, 1993. 